\title{
A HETEROGENEIDADE E DINÂMICAS DA PAISAGEM NA INTERAÇÃO TERRA-ATMOSFERA NO MUNICÍPIO DE NOVA IGUAÇU (RJ) A PARTIR DA APLICAÇÃO DE GEOTECNOLOGIAS LIVRES
}

\author{
MENEZES, Wallace de Araújo - wallacearaujo1801@yahoo.com.br \\ Universidade Federal Rural do Rio de Janeiro/UFRRJ \\ MENDES, Laura Delgado - lauradmendes@gmail.com \\ Universidade Federal Rural do Rio de Janeiro/UFRRJ
}

\begin{abstract}
RESUMO: O artigo tem o objetivo de identificar e analisar a relação entre os padrões de Cobertura e Uso da Terra e as condições de Temperatura da Superfície Terrestre (TST) no município de Nova Iguaçu (RJ) no período entre 1990 e 2015, a partir da utilização de geotecnologias livres. A análise da cobertura e uso da terra, assim como o mapeamento térmico da superfície terrestre através de sensor infravermelho são ferramentas de suma importância para os estudos ambientais, gestão de recursos naturais e para o planejamento ambiental e urbano. $E$, atualmente, têm sido facilitada pela maior disponibilidade de geotecnologias, essenciais nos estudos sobre as alterações antrópicas, assim como para a antecipação e mitigação de impactos. As variações na TST estão diretamente relacionadas com a heterogeneidade da paisagem e mudanças na cobertura e uso da terra. Os mapeamentos foram elaborados com imagens do programa Landsat-5, Landsat-7 e Landsat-8. As cenas adquiridas são da órbita-ponto 217-76 e foram capturadas em dias com tempo estável. Foi utilizada a extensão para classificação supervisionada semiautomática (Semi-Automatic Classification Plugin), na versão 4.0.1, do programa QGIS, versão 2.4. Os resultados indicaram a supressão da vegetação $(4,01 \%)$ e de áreas de pastagens e/ou campos abertos (13,57\%). Por outro lado, observou-se o aumento expressivo da urbanização $(53,7 \%)$, assim como de áreas com solos expostos $(26,07 \%)$. Constatou-se a estreita relação entre as áreas construídas com as maiores temperaturas de superfície estimadas, e que merecem extrema atenção na medida em que influenciam as dinâmicas hidrogeomorfológicas e climáticas em diferentes escalas. Além disso, constatou-se o papel da cobertura vegetal na redução da TST nas áreas de Unidades de Conservação ou mesmo no seu entorno, assim como a sua influência, combinada à rugosidade do relevo, em condições de temperaturas intermediárias entre as áreas mais densamente florestadas e as áreas construídas.
\end{abstract}

Palavras- chaves: temperatura da superfície terrestre; cobertura e uso da terra; clima urbano.

HETEROGENEITY AND LANSCAPE DYNAMICS TO UNDERSTAND THE ROLE OF LANDATMOSPHERE INTERACTIONS IN NOVA IGUAÇU (RIO DE JANEIRO STATE) BY APPLYING FREE GEOTECNOLOGIES

ABSTRACT: This study aims to identify and analyze the relationship between the heterogeneity of land cover and land use and the estimated surface temperatures in Nova Iguaçu, Rio de Janeiro State, using remote sensor data in open-source Geographic Information System. The results revealed the strict connection between densely urbanized areas and the highest estimated surface temperatures, which should deserve careful attention considering its implications for hidrogeomorphology and climate at different scales. Additionally, we identified the land cover role in reducing surface temperatures in and around protected areas, such as its association with surface roughness where surface temperatures are intermediate between densely forested areas and densely urbanized areas. This work also aims to emphasize land-atmosphere interactions as well as highlight possible applications of free geotechnologies for environmental and urban planning.

Keywords: land surface temperature; land cover and land use; urban climate 


\section{INTRODUÇÃO}

As ações antrópicas modificam e adaptam a superfície terrestre, segundo suas necessidades e prioridades, através da extração da cobertura vegetal, impermeabilização do solo, alterações nas redes hidrográficas, entre diversas outras intervenções, o que interfere nas dinâmicas naturais com alterações climáticas em diferentes escalas, assim como nos processos hidrogeomorfológicos no ambiente urbano devido às condições geradas para concentração de massas úmidas (LOMBARDO, 1985).

Um fenômeno climático contemporâneo que ocorre nesses ambientes altamente modificados pela ação antrópica vistos sobre a ordem de grandeza de clima local é o Clima Urbano. Tais alterações são apontadas por Landsberg (1981) como resultantes das transformações que o processo de urbanização gera na superfície, em relação às propriedades radiativas, térmicas, aerodinâmicas e de umidade. Segundo Ribeiro (1993), é sobre as cidades que se dá a maior razão de deterioração da qualidade do ar e do clima, uma vez que nesses espaços são observados dois fatores principais que geram as diferenciações nos climas locais: a intensa artificialização da cobertura do solo e as altas taxas de emissão de poluentes de diversas origens.

Embora os estudos relacionados ao clima urbano já sejam desenvolvidos há algumas décadas, a aplicação de técnicas de sensoriamento remoto representa um avanço relativamente recente e significativo para as pesquisas, com a disponibilização de imagens em resolução cada vez melhor e, especialmente, com diferentes faixas espectrais como as que permitem extrair informações térmicas, essenciais em estudos sobre o clima urbano. Pesquisadores do mundo inteiro têm se dedicado ao tema, inclusive brasileiros e, em especial, com atenção sobre a Região Metropolitana do Rio de Janeiro (LUCENA, 2012).

Nesse sentido, esse artigo tem o objetivo de identificar e analisar a relação entre os padrões de cobertura e uso da terra e as condições de temperatura da superfície terrestre no município de Nova Iguaçu (RJ) no período entre 1990 e 2015, a partir da utilização de geotecnologias livres. Com dados de sensores remotos processados em programa de Sistema de Informações Geográficas de código aberto, buscou-se observar através de processos de modificação da superfície, variações nos índices de temperatura de superfície e, consequentemente, indicativos do que é denominado "Sistema Clima Urbano" (MONTEIRO, 1976). As possibilidades de utilização de técnicas de sensoriamento remoto e geoprocessamento a partir de recursos disponíveis de forma gratuita e de fácil acesso foram essenciais para o desenvolvimento da pesquisa. 0 processamento digital de imagens assume importante papel, principalmente pela aplicação do mapeamento térmico através de sensor infravermelho termal, pois permite, assim, fornecer subsídios para a compreensão dos fenômenos do clima urbano.

O município de Nova Iguaçu (Figura 1) localiza-se na Baixada Fluminense, na Região Metropolitana do Rio de Janeiro (RMRJ) (CEPERJ, 2014). Limita-se com os municípios de Miguel Pereira (norte), Duque de Caxias (nordeste), Japeri (noroeste), Rio de Janeiro (sul), Mesquita (sudeste), Seropédica (sudoeste), Belford Roxo (leste) e Queimados (oeste). Com uma 
área territorial de, aproximadamente, $519,159 \mathrm{~km}^{2}$ e uma população estimada de 807.492 habitantes em 2015 (IBGE), é o maior município da Baixada Fluminense, o segundo maior em área da RMRJ e o quarto mais populoso do estado do Rio de Janeiro.

Desde as décadas de 1960 e 1970 observa-se um rápido e desordenado processo de urbanização, sem um adequado planejamento territorial, devido às mudanças que foram incorporadas por investimentos em empresas públicas e privadas, principalmente na área central do município que permitiram diferentes usos da terra onde se sobressaíram os interesses econômicos em relação aos sociais.

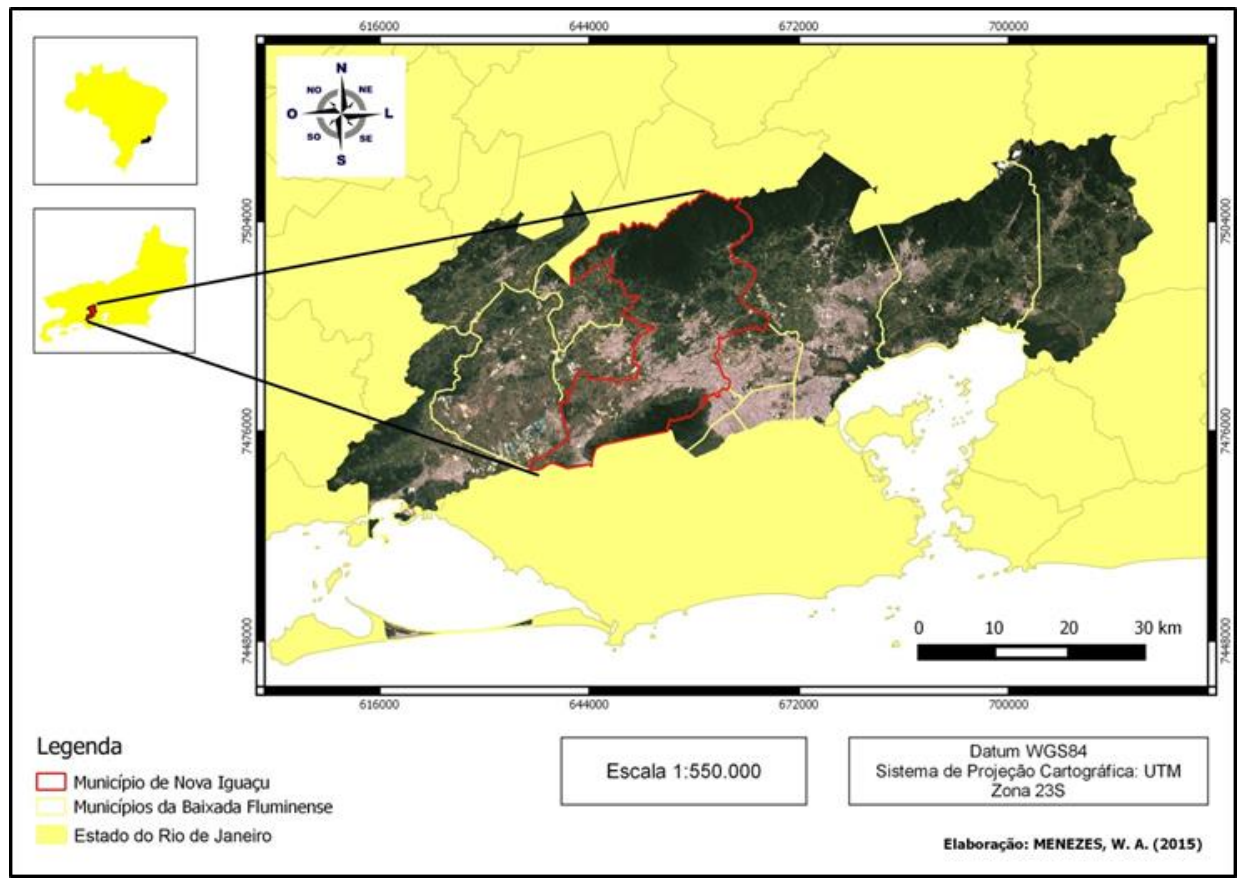

Figura 1 - Mapa dos municípios da Baixada Fluminense a partir de imagem Landsat 8 no ano de 2015, com destaque em vermelho para o município de Nova Iguaçu (RJ), área de estudo do presente trabalho.

Nesse contexto, a área de estudo apresenta disparidades quanto às suas paisagens devido, principalmente, aos diversificados usos e coberturas da terra, e que podem causar a degradação de um ambiente se não consideradas as dinâmicas naturais. Para Bertrand (1971, p. 02) "estudar uma paisagem é antes de tudo apresentar um problema de método" e, tomando a paisagem como unidade sistêmica, o melhor método de análise é o método sistêmico. Neste sentido o autor ainda afirma que

"A paisagem não é a simples adição de elementos geográficos disparatados. É, numa determinada porção do espaço, o resultado da combinação dinâmica, portanto instável, de elementos físicos, biológicos e antrópicos que, reagindo dialeticamente uns sobre os outros, fazem da paisagem um conjunto único e indissociável, em perpétua evolução" (BERTRAND, 1971, p. 02). 
Para Neto (2008), a abordagem sistêmica dentro da Geografia mostra uma tendência de sobreposição conceitual entre paisagem e geossistema, sendo comumente discutidos de forma associada e por vezes considerados a mesma categoria de análise.

Diante das perspectivas apresentadas, fica inerente ao se trabalhar com as possíveis dinâmicas que uma paisagem pode apresentar, e no que se refere a estudos ambientais, ter em mente uma visão sistêmica, não reduzindo a análise da paisagem apenas à soma de seus elementos constituintes, posto que esses aparecem dispostos, interconectados e estruturados de uma determinada maneira e a paisagem, em sua totalidade, deve ser compreendida para além das somas dos elementos disparatados (BERTRAND, 2009).

\section{MATERIAIS E MÉTODOS}

A partir da utilização de dados extraídos de imagens de satélites orbitais em períodos distintos e processados em programa de Sistema de Informações Geográficas (SIGs), buscou-se identificar as alterações na superfície ao longo do tempo. A integração de tais mapeamentos de Cobertura e Uso da Terra aos dados de Temperatura de Superfície Terrestre (TST), obtidos através das bandas termais disponibilizadas pelos sensores remotos, permitiu analisar os seus reflexos na temperatura da superfície e, por sua vez, a sua influência nas condições da atmosfera no contexto do clima urbano.

Os mapeamentos foram elaborados com imagens de satélite do programa Landsat (Land Remote Sensing Satellite), com imagens Landsat-5 (28/03/1990), Landsat-7 (11/01/2000) e Landsat-8 (12/01/2015), todas geradas e disponibilizadas gratuitamente pela National Aeronautics and Space Administration (NASA), em parceria com a United States Geological Survey (USGS), na página Earth Explorer (USGS). As cenas adquiridas são da órbitaponto 217-76, que abrange a Região Metropolitana do Rio de Janeiro, e foram criteriosamente capturadas em dias com tempo estável, todas no período da manhã.

Sobre a escolha das datas, ressaltam-se dois aspectos determinantes para tal recorte temporal: em primeiro lugar as emancipações que o município de Nova Iguaçu sofreu antes do período analisado, impossibilitando, assim, uma analise equivalente entre os anos precedentes e os que se seguiram, com a intensificação, desde a década de 1990, da centralidade urbana no município (ROCHA et al., 2013).

Para a realização da classificação supervisionada da cobertura e uso da terra foi realizado um pré-processamento das imagens. No caso dos dados dos sensores Thematic Mapper (TM) e Enhaced Thematic Mapper Plus (ETM+) a bordo dos satélites Landsat-5 e Landsat-7, respectivamente, os mesmos foram georreferenciados no software SPRING 5.2.7. Para as imagens dos sensores OLI e TIRS, a bordo do satélite Landsat-8, dispensou-se essa etapa, pois já são disponibilizadas ortorretificadas. As imagens dos três satélites foram processadas na extensão para classificação supervisionada semi-automática (Semi-Automatic Classification Plugin), na versão 4.9.2, desenvolvida por 
Congedo (2014) e incorporada no programa Quantum GIS (QGIS), versão 2.12.3.

O processamento dos dados envolveu inicialmente a conversão desses dados de DN (Digital Numbers) para reflectância (TOA - Top of Atmosphere reflectance) e temperatura de brilho (At-Satellite Brightness Temperature). 0 método de correção atmosférica aplicado foi o DOS1 (Dark Objetc Subtration 1). Proposto por Chavez (1989), o DOS1 é um método de correção do espalhamento atmosférico no qual a interferência atmosférica é estimada diretamente a partir dos DN (Digital Numbers) da imagem de satélite, sendo ignorada a absorção atmosférica. Segundo o autor, para a aplicação dessa técnica não há a necessidade de se obter dados sobre as condições atmosféricas na data de obtenção das imagens. No método DOS 1 assume-se que há uma grande probabilidade de existir alvos (pixels) escuros nas imagens, como sombras ocasionadas pela topografia ou por nuvens, os quais deveriam apresentar um DN muito baixo na imagem, equivalente a cerca de $1 \%$ de reflectância (CHAVEZ, 1989). A etapa seguinte de processamento consistiu em definir categorias de interesse por meio da seleção de pontos amostrais que serviram também para a validação da classificação. Cinquenta pontos foram obtidos com o auxílio do programa Google Earth e outros 50 pontos foram coletados com aparelho GPS em etapas de campo na área de estudo. Com isso, realizou-se a seleção de um total de 100 áreas representativas para as classes, designadas como ROIs - Regions Of Interest.

Com base no Manual Técnico de Uso da Terra do IBGE (2006) e nas observações de campo foram definidas as seguintes classes de cobertura e uso da terra: 1 - Vegetação densa; 2 - Áreas Construídas; 3 - Pastagens e/ou Campos Abertos; 4 - Solo exposto; e 5 - Corpos Hídricos.

O método MAXVER foi adotado como algoritmo de classificação, para o qual o valor do limiar deve ser no mínimo 100. Finalmente, executou-se o processamento final dos dados, e obtidos posteriormente os cálculos de área $\left(\mathrm{em} \mathrm{km}^{2}\right)$ e a porcentagem (\%) de cada classe.

Ao final do processo de classificação, as imagens geradas foram verificadas com base nas suas respectivas amostras de treinamento de acordo com os índices de precisão Kappa (K), como descritos na Tabela 1 (MARTINEZ, 2015). O coeficiente Kappa quantifica a concordância entre a escolha de amostras realizadas pelo observador e a escolha feita de forma aleatória, incluindo neste cálculo um fator que subtrai a interferência do acaso.

Tabela 1 - Escala de valor Kappa.

\begin{tabular}{|c|c|}
\hline Coeficiente Kappa & Força da concordância \\
\hline Menor que zero & Poor (insatisfatória) \\
\hline 0 a 0,2 & Slight (desprezível) \\
\hline 0,21 a 0,4 & Fair (suave) \\
\hline 0,41 a 0,6 & Moderate (moderada) \\
\hline 0,61 a 0,8 & Substantial (substancial, grande) \\
\hline 0,81 a 1 & Almost perfect (quase perfeita) \\
\hline
\end{tabular}

Fonte: Martinez (2015). 
Com intenção de descrever o tempo atmosférico e integrar a análise das condições atmosféricas imperantes aos resultados gerados, foram consultadas as cartas sinóticas de superfície a 1000 mb, disponibilizadas pela Diretoria de Hidrografia e Navegação da Marinha do Brasil (DHN). Na imagem do ano de 2015, toda a costa do Rio de Janeiro estava sob ação do Anticiclone do atlântico Sul favorecendo a intensa radiação solar em condições de estabilidade atmosférica com céu claro e calmaria, entre duas isóbaras, uma de 1012 e outra de 1016 mb. Nota-se a impossibilidade de obtenção das cartas sinóticas para o período anterior analisado, disponibilizadas pelo DHN online apenas a partir de outubro de 2006 e, pelo CPTEC/INPE, a partir de setembro de 2008.

Existem estudos sobre o cálculo da temperatura da superfície terrestre como, por exemplo, o Índice de Vegetação por Diferença Normalizada (IVDN) (Normalized Difference Vegetation Index - NDVI) para a estimativa da emissividade da superfície terrestre (SOBRINO et al., 2004) ou utilizando uma classificação de cobertura e uso da terra para a definição da emissividade da superfície da terra de cada classe (WENG et al., 2004). Nesse trabalho, optou-se por obter a estimativa da temperatura da superfície através da reclassificação do raster de classificação de cobertura e uso da terra gerado previamente, usando os valores de emissividade da superfície da terra.

Os índices de emissividade foram baseados em Steinke et al. (2010), considerando as limitações para obtenção direta em campo, sendo eles: áreas construídas: 0,94 ; corpos hídricos: 0,98; vegetação: 0,98; áreas de pastagens e/ou campos abertos: 0,93; e solos expostos: 0,93. Nota-se que esses valores médios podem mascarar alguns resultados, uma vez que as condições ambientais podem modificar os valores de emissividade (STEINKE et al., 2010). Finalmente, foram gerados os mapas com as estimativas da Temperatura da Superfície Terrestre (TST) em kelvin (k), posteriormente convertidas para graus Celsius $\left({ }^{\circ} \mathrm{C}\right)$.

Por fim, foi elaborado um mapeamento das Unidades de Conservação (UC's) presentes no município a partir de dados disponibilizados pelo portal do Cadastro Nacional de Unidades de Conservação (CNUC), com o intuito de relacionar fatores que influenciaram diretamente os valores de TST e os padrões de cobertura e uso da terra, com destaque para a presença de de tais Unidades de Conservação.

\section{RESULTADOS E DISCUSSÃO}

\section{A HETEROGENEIDADE E AS MUDANÇAS NA PAISAGEM DO MUNICÍPIO DE NOVA IGUAÇU: UMA ANÁLISE ESPAÇO-TEMPORAL DA COBERTURA E O USO TERRA.}

As classificações supervisionadas para a Cobertura e Uso da Terra apresentaram os seguintes valores de Índice Kappa Global para os três anos analisados: $1990=0,92 ; 2000=0,82 ;$ e $2015=0,95$. Tais valores correspondem a uma concordância quase perfeita (almost perfect), segundo Martinez (2015) (Tabela 1 ). Os resultados da classificação supervisionada das imagens Landsat nos anos de 1990, 2000 e 2015 estão representados nos mapas de Cobertura e Uso da Terra (Figura 2). 
A Tabela 2 apresenta a síntese dos resultados com a heterogeneidade e evolução da cobertura e uso da terra, incluindo a variação percentual das classes. Observou-se que a classe definida como "Vegetação densa" sofreu uma redução de 4,01\% após um período de 25 anos (1990-2015), assim como da classe identificada como "Pastagens e/ou Campos Abertos", com perda de $13,57 \%$ nesse mesmo período. Registrou-se também um aumento da classe "Solos Expostos" de 26,07\%, assim como uma perda de 6,76\% na classe "Corpos hídricos". No entanto, o aumento da classe "Áreas Construídas" em $53,7 \%$, combinado à supressão da vegetação e de áreas de pastagens e/ou campos abertos, como apontado acima, corroboram com o reconhecido processo de expansão urbana ainda em pleno desenvolvimento no município. Um estudo preliminar realizado na mesma área para o período de 14 anos (2000 e 2014) já indicara a supressão da vegetação, o aumento da urbanização e de áreas com solos expostos (MENEZES \& MENDES, 2015).

Com base nos resultados aqui apresentados, o maior acréscimo ocorreu na classe "Áreas construídas": de 67,496 km², em 1990, para 103,798 km², em 2015. Esse aumento expressivo pode ser devido ao modelo de desenvolvimento econômico adotado que enfatiza a urbanização como sinônimo de "desenvolvimento". Porém, essa ação é, em grande parte, realizada a partir de uma opção de planejamento urbano que não atende aos interesses e necessidades da totalidade da população do município de Nova Iguaçu. É importante também ressaltar que a sua densidade demográfica é de 1527,60 habitantes $/ \mathrm{km}^{2}$, representando a décima mais elevada entre todos os municípios do estado do Rio de Janeiro (IBGE, 2010). Essa concentração pode acabar gerando a convergência de diversas aglomerações populacionais que podem vir a comprometer ainda mais a qualidade ambiental do município pois, de acordo com Monteiro (2003), a cidade é o lugar de mais efetiva interação entre o Homem e a Natureza. A partir da organização primitiva da segunda, o primeiro promove, de maneira concentrada, uma série infindável de derivações que se aglutinam na massa de edificações urbanas ao cabo de que as primitivas condições geo-ecológicas do sítio vão sendo derivadas por acréscimos (MONTEIRO, 2003). 

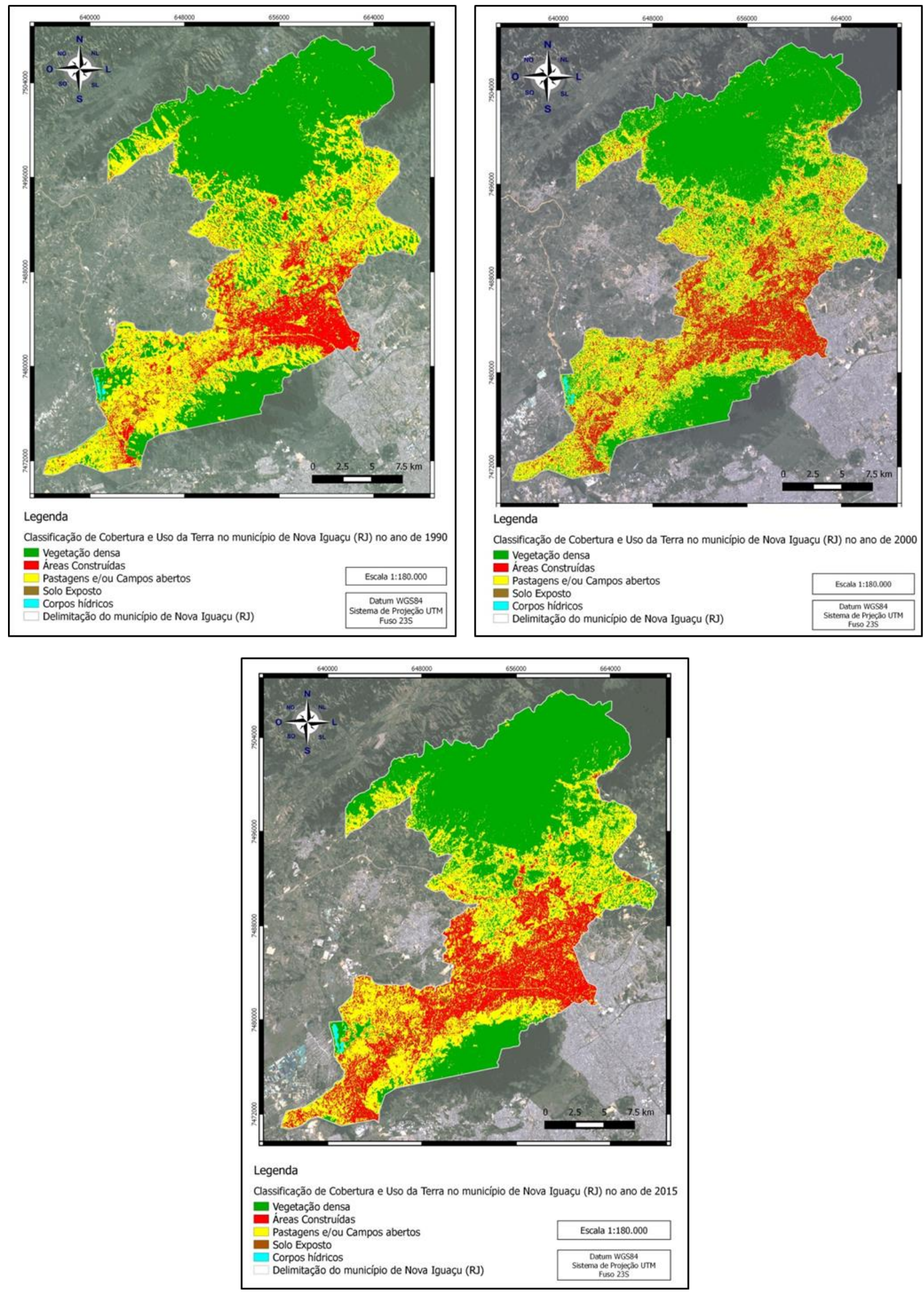

Figura 2 - Mapas de Cobertura e uso da Terra do município de Nova Iguaçu-RJ nos anos de 1990,2000 e 2015 
Tabela 2 - Síntese dos dados da cobertura e uso da terra, referentes aos anos de 1990, 2000 e 2015.

\begin{tabular}{|c|c|c|c|c|c|c|c|}
\hline Classes & $\begin{array}{c}\text { Área } \\
\text { em } \\
1990 \\
\left(\mathrm{~km}^{2}\right)\end{array}$ & $\begin{array}{c}\text { Área em } 1990 \\
(\%)\end{array}$ & $\begin{array}{l}\text { Área em } 2000 \\
\left(\mathrm{~km}^{2}\right)\end{array}$ & $\begin{array}{c}\text { Área em } 2000 \\
(\%)\end{array}$ & $\begin{array}{c}\text { Área } \\
\text { em } \\
2015 \\
\left(\mathbf{k m}^{2}\right)\end{array}$ & $\begin{array}{c}\text { Área } \\
\text { em } \\
2015 \\
(\%)\end{array}$ & $\begin{array}{c}\text { Variação } \\
(\%) \\
\text { (1990- } \\
\text { 2015) }\end{array}$ \\
\hline Vegetação Densa & 235,996 & 45,31 & 232,001 & 44,52 & 226,511 & 143,47 & $-4,01$ \\
\hline Áreas Construídas & 67,496 & 12,95 & 75,67 & 14,54 & 103,798 & 319,92 & $+53,7$ \\
\hline $\begin{array}{c}\text { Áreas de Pastagens e/ou } \\
\text { Campos Abertos }\end{array}$ & 209,881 & 40,27 & 196,005 & 37,61 & 181,386 & 534,81 & $-13,57$ \\
\hline Solos Expostos & 6,697 & 1,28 & 16,444 & 3,15 & 8,443 & 1,62 & $+26,07$ \\
\hline Corpos Hídricos & 1,005 & 0,19 & 0,955 & 0,18 & 0,937 & 0,18 & $-6,76$ \\
\hline TOTAL & 521,075 & 100,0 & 521,075 & 100,0 & 521,075 & 5100,0 & - \\
\hline
\end{tabular}

A figura 3 apresenta o gráfico evolutivo da Cobertura e Uso da Terra do município de Nova Iguaçu destacando, como já mencionado anteriormente, as transformações que ocorreram no período de 1990, 2000 e 2015,e evidenciando a redução gradativa das classes 'Vegetação densa' e 'Pastagens e/ou campos abertos', o aumento progressivo da classe 'Áreas construídas', assim como as variações nas classes 'Solo exposto' e 'Corpos hídricos'.

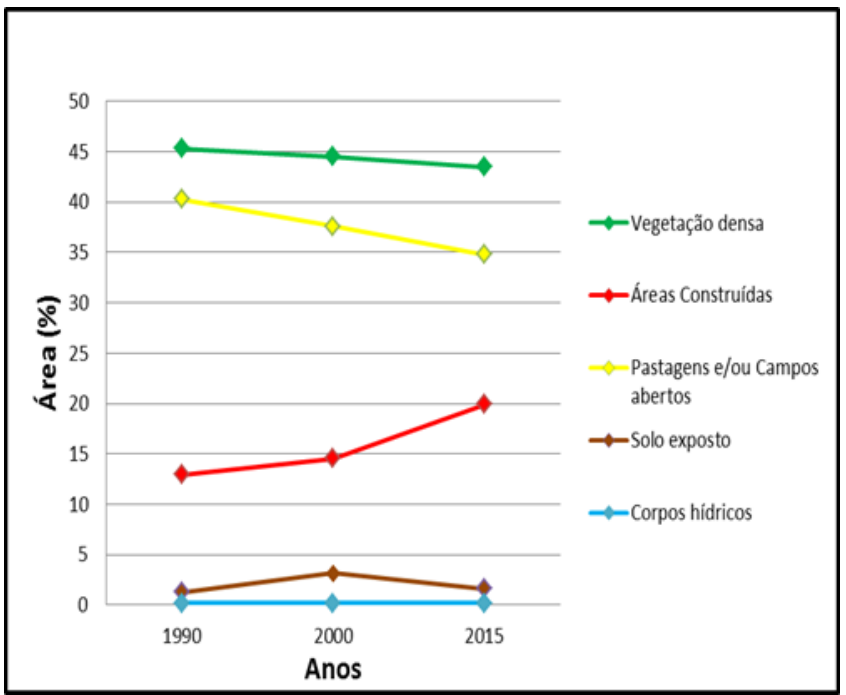

Figura 3 - Gráfico evolutivo da Cobertura e Uso da Terra nos anos 1990, 2000 e 2015.

\section{TEMPERATURA DA SUPERFÍCIE TERRESTRE: SUA INFLUÊNCIA NO CONTEXTO DO CLIMA URBANO.}

De acordo com Jensen (2009) as informações sobre a temperatura superficial podem ser obtidas por sensoriamento remoto, tendo em vista que o calor interno de um alvo é convertido em energia radiante e para a maioria dos alvos existe uma alta correlação positiva entre a temperatura cinética 
verdadeira do alvo e o fluxo radiante proveniente dos mesmos. A temperatura de superfície diz respeito, então, ao deslocamento de calor em função da energia que sai e chega do objeto, sendo de suma importância para o entendimento das interações entre a superfície terrestre e a atmosfera (JENSEN, 2009).

Com o intuito de estimar a Temperatura da Superfície Terrestre (TST), foram realizados dois mapeamentos referentes aos anos de 2000 e 2015 (Figura 4), utilizando as classificações de cobertura e uso da terra geradas previamente para a definição da emissividade da superfície da terra de cada classe.
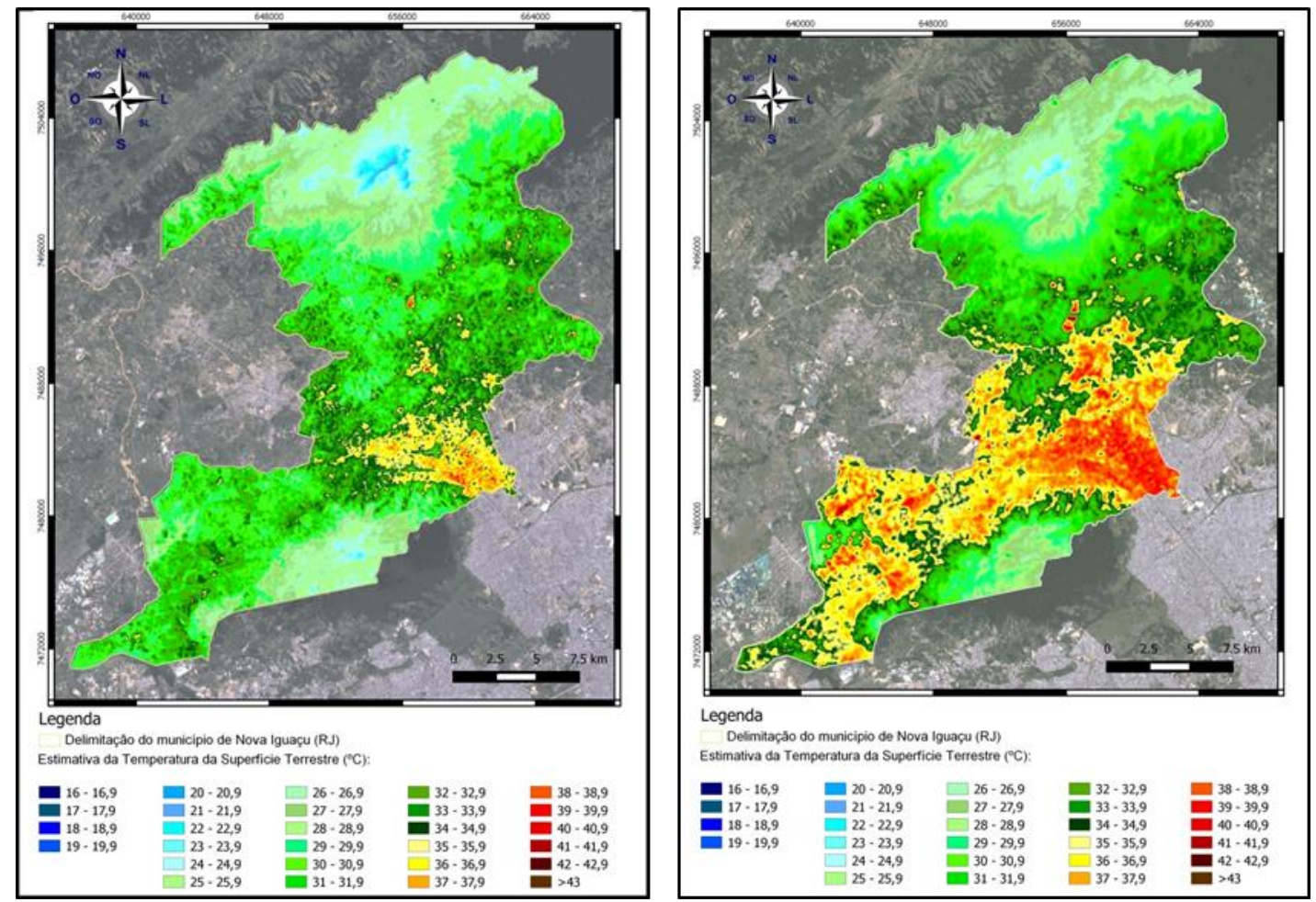

Figura 4 - Mapas de Estimativa da Temperatura da Superfície Terrestre (TST) do município de Nova Iguaçu-RJ nos anos de 2000 e 2015.

Nos dois mapeamentos de TST (Figura 4) verifica-se que as áreas com tonalidade azul escuro registram as menores temperaturas, com valores entre $16^{\circ} \mathrm{C}$ e $24,9^{\circ} \mathrm{C}$, aproximadamente. Essas áreas correspondem aos picos mais elevados do Maciço do Tinguá, ao norte, e do Maciço do Marapicu-GeriçinóMendanha, ao sul.

Os domínios que correspondem aos valores intermediários, com tonalidades verde claro e verde escuro, apresentam os valores de TST entre $26^{\circ} \mathrm{C}$ e $34,9^{\circ} \mathrm{C}$, aproximadamente. As áreas que se destacaram com essas temperaturas são o entorno dos maciços, os morros com altitudes não muito elevadas, muito frequentes nos bairros de Tinguazinho, Adrianópolis, Iguaçu Velho e Tinguá, as áreas de pastagens e/ou campos abertos e algumas localidades com adensamento populacional pouco expressivo. Essas áreas funcionam como ilhas de frescor urbanas - IFU (RIZWAN et al., 2008), em virtude de a vegetação nativa ou remanescentes florestais apresentarem 
singularidades que interceptam a radiação solar, filtrando ou bloqueando totalmente os raios solares.

Os corpos hídricos também funcionam como ilhas de frescor, levando em consideração que grande parte da radiação absorvida é utilizada na evaporação. Além disso, os ventos que circulam nessas áreas resfriam e se deslocam para as áreas adjacentes. Isso ocorre na área da estação de tratamento de água do Guandu, no bairro de Campo Alegre, onde foram estimadas temperaturas intermediárias entre $25^{\circ} \mathrm{C}$ a $29^{\circ} \mathrm{C}$.

No ano 2000 os valores de TST mais elevados se concentravam nos principais núcleos de expansão urbana, localizados no centro do município e em bairros adjacentes. Nesses locais a TST ultrapassa os $40^{\circ} \mathrm{C}$, e estão representados no mapa pelas cores laranja, laranja escuro e vermelho claro. No ano de 2015 os locais com os maiores valores de TST se mantiveram, porém agora ultrapassando os $43^{\circ} \mathrm{C}$ em alguns pontos. O eixo de expansão dessa área mais quente avança na direção leste-oeste, nas proximidades do Maciço Marapicu-Gericinó-Mendanha, no extremo oeste do município e mais ao norte. Essas áreas foram representadas nos mapas pelas tonalidades de cores laranja escuro, vermelho e marrom.

As áreas que registram as maiores temperaturas, podendo ser consideradas como ilhas de calor, foram as que apresentaram estruturas com materiais como: asfalto, concreto, aço e telhas de amianto, que possuem alta reflectância, o que aumenta significativamente a irradiação de calor para a atmosfera (TEZA e BAPTISTA, 2005). Esses materiais são, portanto, responsáveis pela formação da maioria das ilhas de calor das cidades (MONTEIRO, 1976; LOMBARDO, 1985; LIMA, 2005; PAIVA, 2005). A alta irradiação emitida para atmosfera interfere diretamente no balanço de energia de uma área causando um reflexo imediato na temperatura e dando indícios para a geração do Sistema Clima Urbano (MONTEIRO, 2003).

Segundo estudo realizado por Lucena et al. (2012) na Região Metropolitana do Rio de Janeiro, a partir de metodologia baseada na utilização da banda 6 do Landsat, com base em diferentes parametrizações onde a correção atmosférica é realizada utilizando-se medições de estações meteorológicas, os valores de temperatura identificados foram de até $64,5^{\circ} \mathrm{C}$ em Nova Iguaçu para o ano de 2000. Devido à utilização de metodologia diferente, é notório que os resultados não poderiam ser iguais aos apresentados no presente artigo. Porém, cabe destacar a similar espacialidade em que os valores se apresentaram dentro dos limites do município, tanto os mais altos como os mais baixos.

A heterogeneidade $e$ as mudanças da paisagem influenciam significativamente no equilíbrio térmico da superfície urbana em diferentes escalas. Como destaca Ayoade (2002, p. 299), "o homem pode influenciar o clima inadvertidamente através de suas várias atividades e ações, tais como a urbanização, industrialização, desmatamento, atividades agrícolas etc", com o maior impacto do homem sobre o clima associado às áreas urbanas.

Nos mapas de cobertura e uso da terra dos anos 1990, 2000 e 2015 (Figura 2), e como pode ser observado na tabela 2, há uma claro aumento de "áreas construídas", combinado à supressão de áreas com "vegetação densa" e 
de "pastagens e/ou campos abertos", assim como pequenas variações nas classes "solo exposto" e "corpos hídricos".

A partir dessa constatação pode ser feita uma análise integrada dos resultados de cobertura e uso da terra e da TST para o ano de 2015. A classe "vegetação densa" representa as áreas com os menores valores de TST $\left(16^{\circ} \mathrm{C}\right.$ a $\left.24,9^{\circ} \mathrm{C}\right)$, com destaque para os picos mais altos do Maciço do Tinguá ao norte, e do Marapicu-Geriçinó-Mendanha ao sul do município, além de outros locais como em áreas de Unidades de Conservação (BRASIL, 2000) ou locais de difícil acesso para a ocupação, o que garantiu a sua preservação, assim como algumas áreas com a presença de remanescentes de vegetação mais descontínuas que apresentaram TST com resultados um pouco mais elevados $\left(26^{\circ} \mathrm{C}\right.$ a $34,9^{\circ} \mathrm{C}$ ). Nas áreas florestadas, devido à maior densidade de vegetação, a maior parte da energia disponível ao ambiente é distribuída para o processo de evapotranspiração, resfriando a superfície vegetada (BIUDES et al., 2009; LEAL, 2012).

Os dados obtidos são um alerta, pois essa classe sofreu uma diminuição no período de 25 anos (1990-2015) de 9,4 km² (4,01\%), como resultado do processo de desmatamento. A supressão da cobertura vegetal original em substituição por áreas construídas é cada vez mais nítida no município de Nova Iguaçu e contribui também com possíveis modificações nas condições de temperatura na cidade, além dos desequilíbrios e conflitos ambientais já conhecidos.

Combinado a isso, a classe "Áreas construídas" aumentou significativamente no período analisado (1990-2015), em $36,3 \mathrm{~km}^{2}$ (53,7\%). Os altos valores de TST encontrados nas áreas mais densamente urbanizadas estão associados aos diferentes materiais de cobertura, como concreto, aço, telhas e edificações, os quais apresentam alta capacidade de armazenamento térmico. Essa energia térmica contribui para um aumento na temperatura da superfície (MOREIRA e NÓBREGA, 2011; ANDRADE et al., 2013). A substituição da cobertura natural por coberturas como asfalto e concreto altera radicalmente as propriedades radiativas, térmicas, aerodinâmicas e de impermeabilidade da área urbana, o que resulta num incremento da temperatura superficial (DELGADO et al., 2012).

Lucena (2012) já destacava que a classe "urbano" seguia em direção à zona oeste da capital do Estado e às primeiras cidades da Baixada Fluminense que fazem limite com a cidade do Rio de Janeiro, incluindo Nova Iguaçu. Mostrase evidente que essa expansão urbana que adentra para o município de Nova Iguaçu se dá no numa direção leste-oeste no sopé da Serra de Madureira, que integra o Maciço do Marapicu-Geriçinó-Mendanha, ao sul do município, até algumas áreas menos elevadas próximas ao Maciço do Tinguá, ao norte, estando, assim, em concordância com os resultados apresentados por Lucena (2012).

A classe "Solos expostos" também apresentou altos valores de TST $\left(34^{\circ} \mathrm{C}\right.$ a $39^{\circ} \mathrm{C}$ ), com destaque para algumas áreas que margeiam o Arco Metropolitano do Rio de Janeiro (AMRJ) na porção norte do município e terrenos vazios que servem para a instalação de loteamentos para uso residencial e/ou comercial, impulsionados pela especulação imobiliária. Esse fato desperta certa apreensão, pois devem promover modificações na cobertura e uso da terra, muitas delas resultando em pressão e situações de conflito com as Unidades de Conservação, 
como já foi observado na construção da rodovia AMRJ, o que pode trazer transtornos para a população local e alterar ainda mais o balanço térmico da superfície.

Nessa análise da heterogeneidade da paisagem do município de Nova Iguaçu (RJ) composta por aspectos físicos e processos decorrentes de ações antrópicas, alguns efeitos impulsionados pelo último podem trazer prejuízos para a sociedade e alterações nas dinâmicas físico-naturais em uma análise espacial de mesoescala.

As transformações na paisagem no município de Nova Iguaçu, em associação com o aumento das áreas antropizadas, resultou na elevação da TST e, consequentemente, nas condições para a formação das ilhas de calor, como pode ser observado no mapa de Estimativa da Temperatura da Superfície Terrestre do município de Nova Iguaçu-RJ para o ano de 2015 (Figura 4). De acordo com Costa et al. (2010) as propriedades radiativas e térmicas dos materiais urbanos, em particular, albedo, emissividade e capacidade e condutividade térmica, também apresentaram forte influência no desenvolvimento do fenômeno das ilhas de calor, visto que elas determinam como a radiação de ondas curta e longa é refletida, absorvida, emitida e armazenada.

O aumento das áreas construídas representa um motivo de preocupação no que diz respeito à manutenção do equilíbrio térmico da superfície (MENDONÇA e DANNI-OLIVEIRA, 2007), na perda de mata nativa (MONTEIRO, 2003) e nas alterações que tal fator pode causar nos processos hidrogeomorfológicos (MENEZES e MENDES, 2015). Nesse sentido, Landsberg (1981) argumenta que as alterações no balanço de energia são apontadas como resultantes das transformações que o processo de urbanização gera na superfície. Com isso, ressalta-se a necessidade de considerar a heterogeneidade e as modificações das coberturas e dos usos da terra em ambientes urbanos como fatores condicionantes na geração de um clima urbano.

Na configuração da paisagem do município é preciso considerar alguns fatores que influenciaram diretamente os valores de TST e nos padrões de cobertura e uso da terra, com destaque a presença de Unidades de Conservação.

Segundo o Sistema Nacional de Unidades de Conservação - SNUC (BRASIL, 2000), "as Unidades de Conservação possuem objetivos de conservação e limites definidos, sob regime especial de administração, ao qual se aplicam garantias adequadas de proteção". Percebe-se que a presença dessas unidades garantiram uma limitação de áreas construídas e, consequentemente, valores menores de TST. A Figura 5 apresenta a espacialização das Unidades de Conservação no município de Nova Iguaçu, com as suas respectivas áreas (em $\mathrm{km}^{2}$ ). Os mapas de Cobertura e Uso da Terra e de TST do ano de 2015, com a representação dos limites dessas Unidades de Conservação, estão apresentados na Figura 6. 


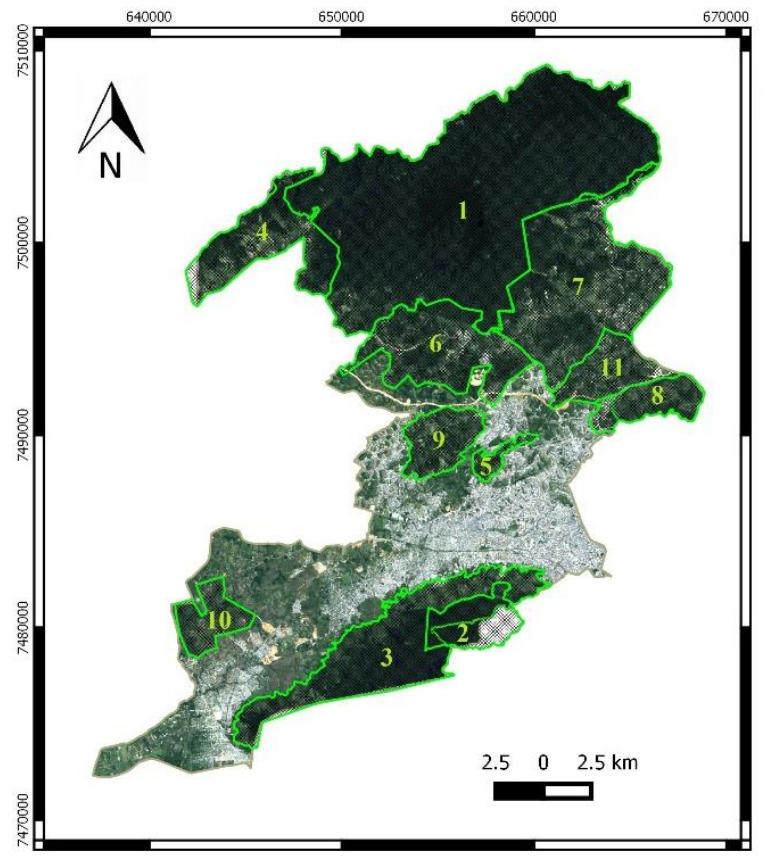

\section{Legenda}

Unidades de Conservação no município de Nova Iguaçu - RJ

1- REBIO de Tinguá - $142.055 \mathrm{~km}^{2}$

2- Parque Municipal - $11.478 \mathrm{~km}^{2}$

3- APA Geriçinó-Mendanha - $44.829 \mathrm{~km}^{2}$

4- APA Jaceruba - $23.648 \mathrm{~km}^{2}$

5- APA Morro Agudo - $2.736 \mathrm{~km}^{2}$

6- APA Rio D'Ouro - $28.556 \mathrm{~km}^{2}$

7- APA Tinguá $-53.808 \mathrm{~km}^{2}$

8- APA Retiro - $10.396 \mathrm{~km}^{2}$

9- APA Tinguazinho - $11.112 \mathrm{~km}^{2}$

10- APA Guanduaçu - $9.074 \mathrm{~km}^{2}$

11- APA Alto Iguaçu $-74.496 \mathrm{~km}^{2}$

TOTAL: $350.181 \mathrm{~km}^{2}(67,45 \%)$

Figura 5 - Unidades de Conservação no município de Nova Iguaçu
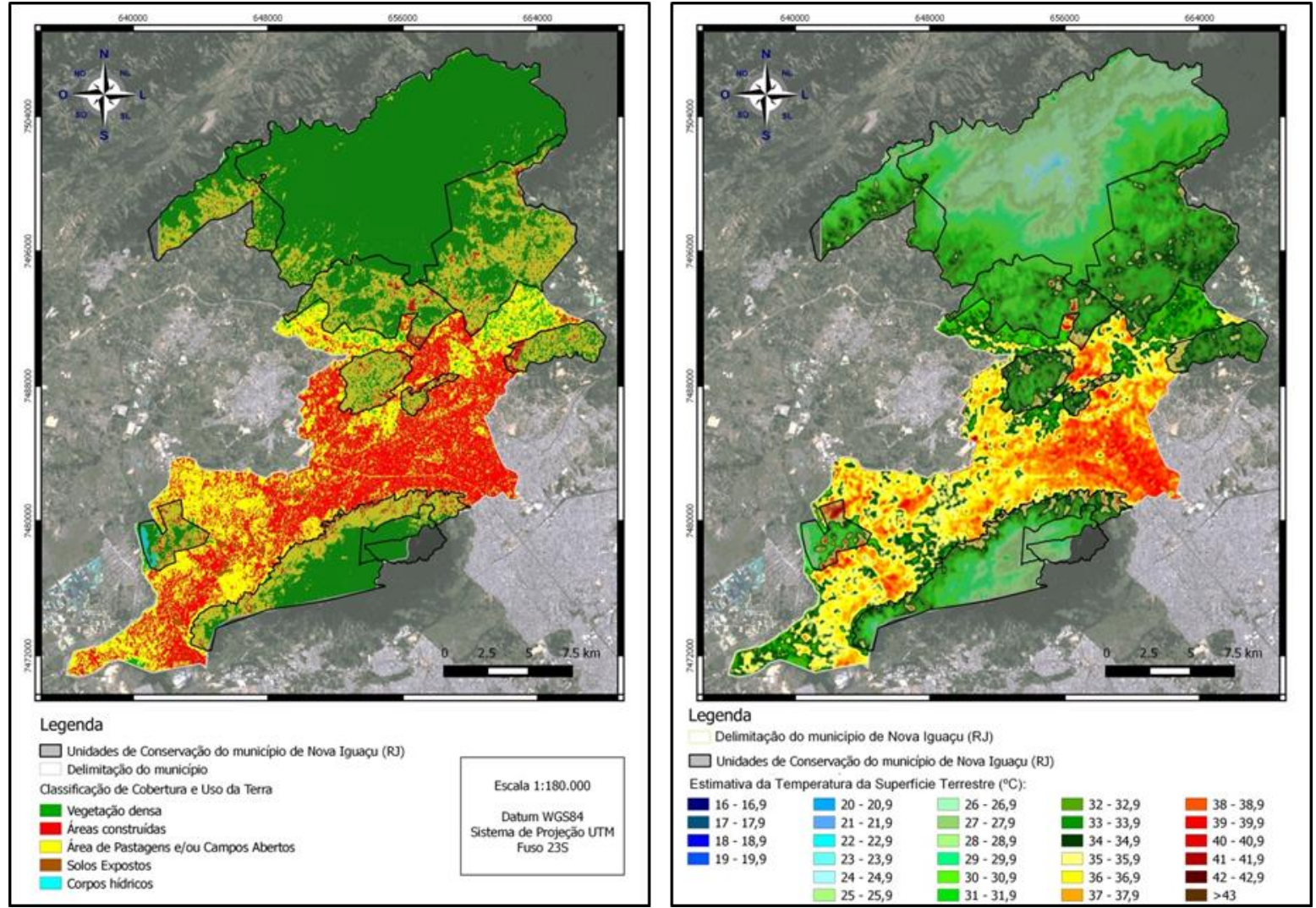

Figura 6 - Cobertura e Uso da Terra, Temperatura de Superfície Terrestre e Unidades de Conservação no ano 2015 


\section{CONCLUSÕES}

As variações na Temperatura da Superfície Terrestre (TST) estão diretamente relacionadas com a heterogeneidade da paisagem e mudanças na cobertura e uso da terra no município de Nova Iguaçu ao longo do período analisado (1990, 2000 e 2015). Os resultados indicaram a supressão da vegetação $(4,01 \%)$ e redução de áreas de pastagens e/ou campos abertos $(13,57 \%)$. Por outro lado, observou-se o aumento expressivo da urbanização $(53,7 \%)$, assim como de áreas com solos expostos $(26,07 \%)$. Além disso, constatou-se o papel da cobertura vegetal na redução da temperatura de superfície nas áreas de Unidades de Conservação ou mesmo no seu entorno próximo.

Nos dois mapeamentos realizados verificou-se que as áreas com as menores temperaturas, tendo seus valores entre $16^{\circ} \mathrm{C}$ até $24,9^{\circ} \mathrm{C}$, aproximadamente, corresponderam às áreas mais elevadas e florestadas dos Maciços do Tinguá e do Marapicu-Geriçinó-Mendanha.

No ano 2000 os valores de TST mais altos se concentravam nos principais núcleos de desenvolvimento na área central do município e bairros adjacentes, que representaram os locais mais abrangentes em que os dados de TST ultrapassam os $40^{\circ} \mathrm{C}$. No ano de 2015 os locais com os maiores valores de TST se mantiveram, porém agora ultrapassando $43^{\circ} \mathrm{C}$ em alguns pontos. Essa área mais quente avança na direção leste-oeste, nas proximidades do Maciço Marapicu-Gericinó-Mendanha, no extremo oeste do município e se expandindo mais ao norte.

Observa-se uma estreita relação entre as áreas construídas com as maiores temperaturas de superfície registradas, e que merecem extrema atenção na medida em que também influenciam as dinâmicas hidrogeomorfológicas e climáticas em diferentes escalas. Esse resultado pode ser atribuído principalmente às transformações locais ocasionadas pelo uso do solo ao longo dos anos.

Como proposta de uma visão sistêmica da paisagem, considera-se aqui que a temperatura da superfície terrestre assume um importante papel no processo de interação entre a superfície terrestre e a atmosfera, visto que boa parte da variação espacial e temporal ocorrida na atmosfera pode ser influência pela superfície terrestre, pelas características e condições das coberturas. Com isso, as transformações continuadas compõem hoje a paisagem do município, aonde vimos que sua heterogeneidade e dinâmicas estão altamente interligadas com as ações antrópicas que ora modificam, ora preservam determinados locais.

Algumas alternativas podem ser adotadas de modo a buscar reverter a TST observada atualmente e/ou não permitir o seu avanço, tais como: melhor planejamento ambiental e urbano, preservando a vegetação remanescente e designação de novas áreas verdes como, por exemplo, criação de novos parques na cidade, e intensificação na fiscalização no que se refere à aplicação das leis ambientais. Outra importante alternativa seria promover e incentivar a arborização urbana, visto que sua presença influencia em dois mecanismos fundamentais para a redução da temperatura nas cidades: o sombreamento e o processo de evapotranspiração (CALLEJAS et al., 2011).

Os resultados obtidos também ressaltam as possibilidades da utilização de técnicas de geoprocessamento e sensoriamento remoto a partir de 
geotecnologias eficientes, de fácil acesso e gratuitas que podem servir de base para um melhor planejamento ambiental e urbano. O programa QGIS e a extensão SCP, mostraram-se bastantes eficazes na classificação da Cobertura e Uso da Terra e na obtenção de dados sobre a Temperatura da Superfície Terrestre. Com isso, busca-se apresentar as possibilidades da utilização de geotecnologias disponíveis de forma gratuita e de fácil acesso que podem servir como instrumentos fundamentais para o estudo do clima urbano.

Ressalta-se que mais levantamentos de campo poderiam refinar ainda mais a classificação de cobertura e uso da terra, assim como a obtenção de dados de emissividade de forma direta ofereceriam maior precisão de dados de temperatura de superfície. Uma outra possibilidade seria a análise de imagens Landsat de estações do ano distintas (como verão e inverno) e até mesmo a utilização de dados de outros satélites para efeito de comparação de resultados.

\section{AGRADECIMENTOS}

Os autores agradecem ao Programa de Iniciação Científica (Institucional e Voluntária) da Universidade Federal Rural do Rio de Janeiro pelo apoio para a realização da pesquisa. Também ao pesquisador Luca Congedo, da Sapienza University of Rome, sempre disponível e atencioso desenvolvedor da extensão Semiautomatic Classification Plugin (SCP), disponível no QGIS, e fundamental para o desenvolvimento da pesquisa. Por fim, aos pareceristas da RBClima pela atenção dispensada e valiosas contribuições no processo de revisão crítica desse artigo.

\section{REFERÊNCIAS}

ANDRADE, S. C. P.; VIEIRA, V. R.; MORAIS, H. F.; ALBUQUERQUE, E. M.; SANTOS, C. A. C. Estimativa de albedo, NDVI e Temperatura de Superfície no município de Santarém-PA. In: XVI SIMPÓSIO BRASILEIRO DE SENSORIAMENTO REMOTO - SBSR, 2013, Foz do Iguaçu, PR: INPE, p. 11291135.

AYOADE, J. O. Introdução à climatologia para os Trópicos. Rio de Janeiro: Bertrand Brasil, 2002.

BERTRAND, C.; BERTRAND, G. Uma geografia transversal e de travessias: o meio ambiente através dos territórios e das temporalidades. Tradução de Messias Modesto dos Passos. Maringá: Massoni, 2009, 358 p.

BERTRAND, G. Paisagem e Geografia Física global: esboço metodológico. Caderno de Ciências da Terra, n.13, 1971. 27 p.

BIUDES, M.S.; CAMPELO JUNIOR, J.H.; NOGUEIRA, J.S.; SANCHES, L. Estimativa do balanço de energia em cambarazal e pastagem no norte do Pantanal pelo método de razão de Bowen. Revista Brasileira de Meteorologia, São José dos Campos - SP, v.24, n.2, p. 135 - 143, 2009.

BRASIL. Lei no 9.985/2000, que instituiu o Sistema Nacional de Unidades de Conservação (SNUC). Disponível em <http://www.mma.gov.br/port/conama/legiabre.cfm?codlegi=322> Acesso em 05 de abril de 2016. 
CALlejAS, I. J. A.; DURANTE, L. C.; OliveirA, A. S.; NOGUEIRA, M. C. J. A. Uso do solo e temperatura superficial em área urbana. Mercator, Fortaleza - $C E$, v. 10, n.23, p. 207-223, 2011.

CEPERJ. Mapa Estado do Rio de Janeiro - Regiões de Governo e Municípios 2014. Fundação Centro Estadual de Estatísticas, Pesquisas e Formação de Servidores Públicos do Rio de Janeiro. Disponível em <http://www.fesp.rj.gov.br/ceep/info_territorios/Reg\%20Gov_2013.pdf> Acesso em 03 de abril de 2016.

CHAVEZ, P.S. Radiometric calibration of Landsat thematic mapper multispectral images. Photogrammetric Engineering and Remote Sensing, v. 55, p. 12851294, 1989.

CONGEDO, L. Tutorial: Land Cover Classification Using the Semiautomatic Classification Plugin v. 3.0 "Rome" for QGIS. Disponível em <http://fromgistors.blogspot.com/> Acesso em 24 de outubro de 2014.

COSTA, D.F.; SILVA, H.R.; PERES, L.F. Identificação de ilhas de calor na área urbana de Ilha Solteira - SP através da utilização de geotecnologias. Revista Engenharia Agrícola, Jaboticabal - SP, v.30, n.5, p.974-985, 2010.

DELGADO, R.C.; RODRIGUES, R. A.; FARIA, A.L.L.; PESSOA, C.S.; DAHER, M. Uso do sensoriamento remoto na estimativa dos efeitos de ilhas de calor. Revista Brasileira de Ciências Ambientais, Rio de Janeiro - RJ, v.25, p. 69-80. 2012.

IBGE. Instituto Brasileiro de Geografia e Estatística. Banco de dados do IBGE 2015. Disponível em: <http://www.cidades.ibge.gov.br/perfil/nova-iguacu/> Acesso em: 12 de janeiro de 2016.

IBGE. Instituto Brasileiro de Geografia e Estatística. Censo 2010. Disponível em: <http://censo2010.ibge.gov.br/> Acesso em 12 de janeiro de 2016.

IBGE. Instituto Brasileiro de Geografia e Estatística. Manual Técnico de Uso da Terra. Manuais Técnicos em Geociências. $2^{\circ}$ ed., n. 7,. Rio de Janeiro: IBGE, 2006.

JENSEN, J. R. Sensoriamento Remoto do Ambiente: uma perspectiva em recursos terrestres. São José dos Campos: Editora Parêntese, 2009.

LANDSBERG, H. E. The Urban Climate. New York: International Geophysics Series, Vol.28, Academic Press, 1981.

LEAL, L. A influência da vegetação no clima urbano da cidade de Curitiba - PR. 2012. Tese (Doutorado em Engenharia Florestal). Setor de Ciências Agrárias, Universidade Federal do Paraná. Curitiba - PR.

LIMA, L.P. Clima e forma urbana: métodos de avaliação do efeito das condições climáticas locais nos graus de conforto térmico e no consumo de energia elétrica em edificações. 2005. Dissertação (Mestrado em Tecnologia) - Centro Federal de Educação Tecnológica do Paraná, Curitiba - PR.

LOMBARDO, M. A. Ilha de Calor nas Metrópoles. O Exemplo de São Paulo. São Paulo: Hucitec, 1985. 
LUCENA, A. J. A ilha de calor na região metropolitana do Rio de Janeiro. 2012. Tese (Doutorado em Ciências Atmosféricas) - Programa de Engenharia Civil, COPPE/UFRJ, Rio de Janeiro - RJ.

LUCENA, A. J.; FILHO, O. C. R.; PERES, L. F.; FRANÇA, J. R. A. A evolução da ilha de calor na região metropolitana do Rio de Janeiro. Revista Geonorte, Amazonas, v.2, n.5, p. $8-21,2012$.

MARTINEZ, E. Z. Coeficiente kappa (vídeo aula). Disponível em: <https://www.youtube.com/watch?v=OGKFThOEPoc>. Acesso em: $13 \mathrm{de}$ dezembro de 2015

MENDONÇA, F.; DANNI-OLIVEIRA, I. M. Climatologia: noções básicas e climas do Brasil. São Paulo: Oficina de Texto, 2007.

MENEZES, W. A.; MENDES, L.D. Mapeamento da temperatura de superfície e da cobertura e uso da terra com geotecnologias livres para uma análise preliminar da relação terra-atmosfera no município de Nova Iguaçu (RJ). Revista Equador, Teresina - PI, v. 4, Edição especial 02, p. 1160-1167, 2015.

MONTEIRO, C. A. de F.; MENDONÇA, F. Clima Urbano. São Paulo: Contexto, 2003.

MONTEIRO, C. A. de F. Teoria e Clima Urbano. Série "Teses e Monografias" no 25. São Paulo, Instituto de Geografia da USP, 1976.

MOREIRA, E. B. M.; NOBREGA, R. S. Uso de imagens multiespectrais aplicada à análise espaço-temporal dos padrões de temperatura e albedo da superfície. In: XV SIMPÓSIO BRASILEIRO DE SENSORIAMENTO REMOTO - SBSR, 2011, Curitiba - PR, INPE p.776 - 782.

NETO, R. M. A abordagem sistêmica e os estudos geomorfológicos: algumas interpretações e possibilidades de aplicação. Revista Geografia, v. 17, n. 2, jul./dez., p. 67-87, 2008.

PAIVA, C. M. Estimativa do balanço da energia e da temperatura da superfície via satélite NOAA-AVHRR. 2005. Tese (Doutorado em Ciências da Engenharia Civil) - COPPE-UFRJ, Rio de Janeiro - RJ.

RIBEIRO, A.G. As escalas do clima. Boletim de Geografia Teorética, México, v.23, n.45/46, p. 288-294, 1993.

RIZWAN, A. M., DENNIS, Y.C., LEUNG, L. C. A review on the generation, determination and mitigation of Urban Heat Island. Journal of Environmental Sciences, v. 20, p. 120-128, 2008.

ROCHA, A. S.; MAGALHÃES, A. L.; SANTANA M. C.; FILHO, S. C. S. Alma(naque)... da Baixada. Rio de Janeiro: APPH-CLIO, 2013.

SOBRINO, J. A.; JIMÉNEZ-MUÑOZ, J. C.; PAOLINI, L. Land surface temperature retrieval from LANDSAT TM 5. Remote Sensing of Environment, n. 90, p. 434440, 2004.

STEINKE, V. A; STEINKE, E. T; SAITO, C. H. Estimativa da temperatura de superfície em áreas urbanas em processo de consolidação: reflexões e experimento em Planaltina-DF. Revista Brasileira de Climatologia, Curitiba - PR, v. 6, p. 37-56, 2010. 
TEZA, C. T. V.; BAPTISTA, G. M. de M. Identificação do fenômeno ilhas urbanas de calor por meio de dados ASTER on demand 08 - Kinetic Temperature (III): metrópoles brasileiras. In: XII SIMPÓSIO BRASILEIRO DE SENSORIAMENTO REMOTO - SBSR, 2005, Goiânia - GO, INPE, p. 3911 - 3918.

USGS. United States Geological Survey. Earth Explorer. Disponível em: <http://earthexplorer.usgs.gov> Acesso em 24 de janeiro de 2016.

WENG, Q.; LU, D.; SCHUBRING, J. Estimation of land surface temperaturevegetation abundance relationship for urban heat island studies. Remote Sensing of Environment, v.89, p. 467-483, 2004. 